Available online on 15.07.2017 at http://iddtonline.info
Journal of Drug Delivery and Therapeutics
Open access to Pharmaceutical and Medical research
(2011-17, publisher and licensee JDDT, This is an Open Access article which permits unrestricted
noncommercial use, provided the original work is properly cited

Open $\odot$ Access

Research Article

\title{
FORMULATION DEVELOPMENT AND EVALUATION OF 5-FLUROURASIL AND ECONAZOLE GEL USING RICE BRAN WAX
}

\author{
Rajeev Malviya*, Dr. M.D. Khirsagar, Dr. A.V. Chandewar
}

Sant Gadge Baba Amravati University, Amravati, Maharashtra, India

\begin{abstract}
Besides delivering drug to the body, a drug delivery system aims to improve patient compliance, patient acceptance. The dosage forms available for the delivery of topical agents include ointment, paste, lotion, moisturizing cream and powder. However, Gel is more preferable due to their properties. Present research work is attempted to develop gel by using rice bran wax. Rice bran wax is the vegetable wax extracted from rice bran oil. The oil generally contains 2-6\% wax. However it is assumed that on an average it contains $3 \%$ wax. Physicochemical tests such as globule size, evaluation of the intrinsic viscosity and homogeneity of Gel products, have been traditionally used to provide reasonable evidence of consistent product performance. However, for the purposes of these studies, the final gel products were characterized for their clarity, $\mathrm{pH}$, viscosity, spread ability, skin irritation test and in vitro diffusion studies using standard procedure. All the results match with official specifications.
\end{abstract}

Keywords: Gel, Rice Bran Wax, Econazole, 5-Fluorouracil

Article Info: Received 14 May, 2017; Review Completed 24 June, 2017; Accepted 24 June, 2017; Available online 15 July, 2017

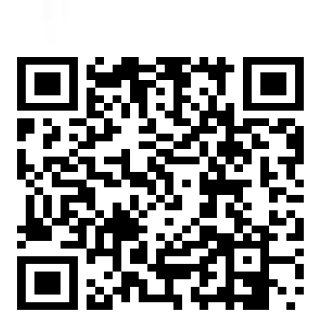

Cite this article as:

Malviya R, Khirsagar MD, Chandewar AV, Formulation development and evaluation of 5-flurourasil and econazole gel using rice bran wax, Journal of Drug Delivery and Therapeutics. 2017; 7(4):51-58

DOI: http://dx.doi.org/10.22270/jddt.v7i4.1464

*Address for Correspondence

Rajeev Malviya, Sant Gadge Baba Amravati University, Amravati, Maharashtra, India

Email: rajeevmalviya33@gmail.com

\section{INTRODUCTION}

Waxes (animal and plants) are esters of high molecular weight monohydroxy alcohols and high molecular weight carboxylic acids. They are chemically different from fats and oils, from hydrocarbon or paraffin waxes, and from synthetic polyether waxes such as carbowax ${ }^{1}$. During the past few decades a number of non conventional vegetable oils have been accepted as good quality edible oils in India and in other countries. Since India is one of the principle producers of rice in the world enormous stress is laid upon the extraction of oil from rice bran. Rice bran is the brown layer between the rice and outer husk of the paddy. The bran is obtained as the by-product in rice milling. Rice bran contains around $15-20 \%$ of oil, which can be economically obtained only by solvent extraction process. Rice bran oil is now gaining importance as one of the edible oils in India because of its nutritional property. Crude rice bran wax is dark brown in color and has its own typical physical and chemical composition. The literature survey reveals that rice bran wax has been used in cosmetics and toiletries. Unfortunately the details of this literature are not available. Rice bran wax is also utilized as an ingredient for coating candy and chewing gums. But the utilization of rice bran wax in pharmaceuticals is meager or hardly there is any report inspite of large production. Therefore the rice bran wax utilization in pharmaceuticals is worth investigating. Keeping in view the potential availability of rice, its contents such as oils and wax an attempt is made to utilize rice bran wax as pharmaceutical aid.

Recent work indicates that rice bran wax is mainly an ester of lignoceric acid and myricyl alcohol. The hard nontacky wax separately recovered is reported to be chiefly melissyl cerotate and melts at about $80-85^{\circ}$. Research had showed that the properties of the refined and bleached wax are similar to those of presently imported carnauba wax ${ }^{2}$. Present study attempts to find if rice bran wax is useful as gel base. The gel base is prepared by using rice bran wax 
and evaluated for their clarity, $\mathrm{pH}$, viscosity, spreadability, skin irritation test and in vitro diffusion studies using standard procedure.

\section{MATERIALS AND METHODS}

Econazole and $5 \mathrm{FU}$ of pharmaceutical grade were obtained as gift sample from Euphoria ealthcare Pvt. Ltd. Mumbai. Rice bran wax obtained from Triveni Interchem Pvt Ltd. Vapi, Gujarat, India. All other reagents and chemicals used were of analytical reagent grade.

\section{Formulation development Gel}

Appropriate quantity of carbopol 934 and rice bran wax were soaked in water for a period of 2 hours. Carbopol and rice bran wax was then neutralized by adding triethanolamine (TEA) with stirring. Then required amount of drug was dissolved in appropriate and pre weighted amounts of propylene glycol and ethanol. Then solvent blend was transferred to carbopol and rice bran wax container and agitated for $20 \mathrm{~min}$. The dispersion was then allowed to hydrate and swell for $60 \mathrm{~min}$, finally $\mathrm{pH}$ was adjusted to $6.8-7.0$ by adding $98 \%$ TEA until the desired $\mathrm{pH}$ value was reached. During $\mathrm{pH}$ adjustment, the mixture was stirred gently with a spatula until homogeneous gel was formed. All the samples were allowed to equilibrate for 24 hours at room temperature prior to performing rheological measurements ${ }^{3,4,5}$

\section{Formulation development of gel of econazole}

Table 1: Formulation $\mathrm{G}_{\mathrm{E} 1}$ to $\mathrm{G}_{\mathrm{E} 9}$

\begin{tabular}{|c|c|c|c|c|c|c|c|c|c|}
\hline \multirow{2}{*}{$\begin{array}{c}\text { Ingredient } \\
(\% \text { w/w })\end{array}$} & \multicolumn{9}{|c|}{ Formulation Code } \\
\cline { 2 - 12 } & GE1 & GE2 & GE3 & GE4 & GE5 & GE6 & GE7 & GE8 & GE9 \\
\hline Econazole & 1 & 1 & 1 & 1 & 1 & 1 & 1 & 1 & 1 \\
\hline Carbopol & 0.1 & 0.15 & 0.2 & 0.25 & 0.30 & 0.35 & 0.40 & 0.5 & 0.55 \\
\hline Rice bran wax & 0.55 & 0.50 & 0.45 & 0.40 & 0.35 & 0.30 & 0.25 & 0.20 & 0.15 \\
\hline Propylene Glycol & 0.2 & 0.2 & 0.2 & 0.2 & 0.2 & 0.2 & 0.2 & 0.2 & 0.2 \\
\hline Triethanolamine & 2 & 2 & 2 & 2 & 2 & 2 & 2 & 2 & 2 \\
\hline Methyl Paraben & 0.2 & 0.2 & 0.2 & 0.2 & 0.2 & 0.2 & 0.2 & 0.2 & 0.2 \\
\hline Propyl paraben & 0.2 & 0.2 & 0.2 & 0.2 & 0.2 & 0.2 & 0.2 & 0.2 & 0.2 \\
\hline Distill. water & q.s & q.s & q.s & q.s & q.s & q.s & q.s & q.s & q.s \\
\hline
\end{tabular}

\section{Formulation development of gel of 5-fluorouracil}

Table 2: Formulation $\mathrm{G}_{\mathrm{F} 1}$ to $\mathrm{G}_{\mathrm{F} 9}$

\begin{tabular}{|l|l|l|l|l|l|l|l|l|l|}
\hline \multirow{2}{*}{ Ingredient (\% w/w) } & \multicolumn{9}{l}{ Formulation Code } \\
\cline { 2 - 12 } & GF1 & GF2 & GF3 & GF4 & GF5 & GF6 & GF7 & GF8 & GF9 \\
\hline Econazole & 1 & 1 & 1 & 1 & 1 & 1 & 1 & 1 & 1 \\
\hline Carbopol & 0.1 & 0.15 & 0.2 & 0.25 & 0.30 & 0.35 & 0.40 & 0.5 & 0.55 \\
\hline Rice bran wax & 0.55 & 0.50 & 0.45 & 0.40 & 0.35 & 0.30 & 0.25 & 0.20 & 0.15 \\
\hline Propylene Glycol & 0.2 & 0.2 & 0.2 & 0.2 & 0.2 & 0.2 & 0.2 & 0.2 & 0.2 \\
\hline Triethanolamine & 2 & 2 & 2 & 2 & 2 & 2 & 2 & 2 & 2 \\
\hline Methyl Paraben & 0.2 & 0.2 & 0.2 & 0.2 & 0.2 & 0.2 & 0.2 & 0.2 & 0.2 \\
\hline Propyl paraben & 0.2 & 0.2 & 0.2 & 0.2 & 0.2 & 0.2 & 0.2 & 0.2 & 0.2 \\
\hline Distill. water & q.s & q.s & q.s & q.s & q.s & q.s & q.s & q.s & q.s \\
\hline
\end{tabular}

\section{Evaluation of gel}

Characterization of developed formulation ${ }^{4,6,7,8}$

Gel was evaluated for their clarity, $\mathrm{pH}$, viscosity, spreadability, skin irritation test, in vitro diffusion studies using standard procedure.

\section{Psychorheological Characteristic}

The Psychorheological Characteristic was checked for gel formulations (colour, clogging, homogeneity and texture) and observations.

\section{Consistency or hardness of gel}

It was measured by Penetrometer. Three samples were stored at $25+0.50 \mathrm{C}$ and with shear for $5 \mathrm{~min}$. Three samples were melted and carefully and completely filled three containers, without forming air bubbles stored at 25+ $0.50 \mathrm{C}$ for $24 \mathrm{hrs}$. Test samples were placed on Penetrometer. Penetrating object was released for $5 \mathrm{sec}$. Depth of penetration was measured.

\section{Washability}

Gel Formulations were applied on the skin and then ease and extent of washing with water were checked manually and observations.

\section{Extrudability study}

The gel formulations were filled into collapsible metal tubes or aluminium collapsible tubes. The tubes were pressed to extrude the material and the extrudability of the formulation was checked.

\section{Spreadability}

Two glass slides of standard dimensions $(6 \times 2)$ were selected. The gel formulation whose spreadability had to be determined was placed over one of the slides. The second slide was placed over the slide in such a way that the formulation was sandwiched between them across a length of $6 \mathrm{cms}$ along the slide. 100 grams of weight was placed up on the upper slide so that the topical gel formulation between the two slides was traced uniformly to form a thin layer. 
The weight was removed and the excess of the gel formulation adhering to the slides was scrapped off. The lower slide was fixed on the board of the apparatus and one end of the upper slide was tied to a string to which 20 gram load could be applied 50with the help of a simple pulley. The time taken for the upper slide to travel the distance of 6 $\mathrm{cms}$ and separate away from lower slide under the direction of the weight was noted. The experiment was repeated and the average of 6 such determinations was calculated for each topical gel formulation.

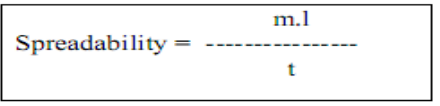

Where, $\mathrm{S}=$ Spreadability $(\mathrm{gcm} / \mathrm{sec})$

$\mathrm{m}=$ weight tied to the upper slide (20 grams)

$1=$ length of glass slide $(6 \mathrm{cms}) . \quad t=$ time taken is seconds.

\section{Determination of $\mathrm{pH}$}

The $\mathrm{pH}$ of the gel was determined by digital $\mathrm{pH}$ meter.

\section{Viscosity}

The measurement of viscosity of the prepared gel was done using Brookfield digital Viscometer.

\section{In-vitro drug release studies using the prehydrated} cellophane membrane

\section{- Preparation of cellophane membrane for the} diffusion studies:

The cellophane membrane approximately $25 \mathrm{~cm}$ x $2 \mathrm{~cm}$ was taken and washed in the running water. It was then soaked in distilled water for 24 hours, before used for diffusion studies to remove glycerin present on it and was mounted on the diffusion cell for further studies.

\section{- Diffusion Studies:}

The in-vitro diffusion of drug from the different gel preparations were studied using the classical standard cylindrical tube fabricated in the laboratory; a simple modification of the cell is a glass tube of $15 \mathrm{~mm}$ internal diameter and $100 \mathrm{~mm}$ height. The diffusion cell membrane was applied with one gram of the formulation and was tied securely to one end of the tube, the other end kept open to ambient conditions which acted as donor compartment. The cell was inverted and immersed slightly in $250 \mathrm{ml}$ of beaker containing phosphate buffer, freshly prepared $(\mathrm{pH}$ 7.4) as a receptor base and the system was maintained for 2 hrs at $37 \pm 0.5^{\circ} \mathrm{C}$. Aliquots, each of $5 \mathrm{ml}$ volume were withdrawn periodically at predetermined time interval of $15,30,45,60,90,120 \mathrm{~min}$ and replaced by an equal volume of the receptor medium. The aliquots were suitably diluted with the receptor medium and analyzed by UV-Vis spectrophotometer at $233.0 \mathrm{~nm}$ for econazole and $264 \mathrm{~nm}$ for 5-FU using phosphate buffer as blank.

\section{Data Analysis via drug release kinetics $\operatorname{study}^{8-10}$}

The results of in-vitro release profile obtained for all the formulations were plotted in kinetic models as follows,

1. Cumulative of drug released versus time (zero order kinetic model).

2. Log cumulative percent drug remaining to be absorbed versus time (First order model)

3. Cumulative amount of drug release versus square root of time (Higuchi model)
4. Log cumulative drug released versus log time (Korsmeyer-Peppas model)

\section{Zero order release kinetics:}

Zero order release would be predicted by the following equation,

$\mathrm{Q}_{\mathrm{t}}=\mathrm{Q}_{\mathrm{O}}+\mathrm{Kt}$

Where, Qt is the amount of drug dissolved in time $t$,

$\mathrm{Q}_{0}$ is the initial amount of drug in the solution (most times, $\mathrm{Q}_{0}=0$ ) and $\mathrm{K}$ is the zero order release constant.

\section{First order release kinetics:}

First order release would be predicted by the following equation,

$$
Q_{t}=Q_{0} e^{-K_{1} t}
$$

Where, Qt is the amount of drug released in time t, $\mathrm{Q}_{0}$ is the initial amount of drug in the solution and $\mathrm{K}$ is the first order release constant.

\section{Higuchi kinetics:}

This equation describes drug release as a diffusion process based on the Flick's Law, Square root time dependent.

$$
\mathrm{Q}=\mathrm{Kt}^{1 / 2}
$$

$\mathrm{Q}=$ Amount of drug release per unit area in time $\mathrm{t}$, $\mathrm{K}=$ release rate constant

\section{Peppas \& korsemeyer equation}

The amount of drug released at time $\mathrm{t}(\mathrm{Mt})$ with respect to the total amount of drug released $\left(\mathbf{M}_{\infty}\right)$, can be expressed in terms of an exponential expression as follows:

$$
\mathrm{M}_{\mathrm{t}} / \mathrm{M}_{\infty}=\mathrm{kt}^{\mathrm{n}}
$$

Where, $M_{t} / M_{\infty}=$ The fraction of drug released at time $t$, $\mathrm{K}=$ Constant incorporating the structural and geometrical characteristic of the drug /polymer system.

$\mathrm{n}=$ diffusion exponent related to the release

\section{Skin irritation studies of developed formulations ${ }^{8,10}$}

\section{Animals:-}

Wistar rats (150-200 g) were group housed $(n=6)$ under a standard $12 \mathrm{~h}$ light/dark cycle and controlled conditions of temperature and humidity $\left(25 \pm 2{ }^{\circ} \mathrm{C}\right)$. Rats received standard rodent chow and water ad libitum. Separate group $(n=6)$ of rats was used for each set of experiments. The animal studies were approved by the Institutional Animal Ethics Committee (IAEC), constituted for the purpose of control and supervision of experimental animals by Ministry of Environment and Forests, Government of India, New Delhi, India.

\section{Skin irritation study}

The rats were divided into three groups $(n=4)$ and formulations were topically applied, i.e. The formulations were uniformly applied over the shaven skin of rats. The skin was observed for any visible changes such as erythema (redness) or edema at 24,48 , and $72 \mathrm{~h}$ after the application of various formulations, and the primary irritation index was calculated. For each animal, the primary irritation scores were added together for the test formulation for both erythema and edema at each time specified and divided by the total number of observations. The scores for each animal was added and divided by the total no of animals to give the primary irritation index. The primary irritation index was characterized by number (score) and description (response category). 
Group V - Formulation II (Gel)

\section{Statistical analysis}

The values were expressed as mean \pm SEM. The statistical significance was assessed using one-way analysis of variance (ANOVA) followed by Tukey's test and $\mathrm{P}<0.05$, $\mathrm{P}<0.01$, and $\mathrm{P}<0.001$ were considered to be statistically significant.

\section{In-vitro antifungal activity}

\section{Media preparation (broth and agar media)}

Composition of Potato Dextrose agar media;

$\begin{array}{ll}\text { Agar } & -\quad 20 \text { gms. } \\ \text { Potato infusion } & -\quad 200 \text { gms. } \\ \text { Dextrose infusion } & -\quad 20 \text { gms. } \\ \text { Distilled water } & -\quad \text { to make } 1000 \mathrm{ml} . \\ \text { pH } & -7\end{array}$

\section{Method of preparation}

This agar medium was dissolved in distilled water and boiled in conical flask of sufficient capacity. Dry ingredients are transferred to flask containing required quantity of distilled water and heat to dissolve the medium completely.

\section{Sterilization culture media}

The flask containing medium was cotton plugged and was placed in autoclave for sterilization at $15 \mathrm{lbs} / \mathrm{inch}^{2}\left(121^{\circ} \mathrm{C}\right)$ for 15 minutes.

\section{Preparation of plates}

After sterilization, the potato dextrose agar in flask was immediately poured $(20 \mathrm{ml} /$ plate $)$ into sterile Petri dishes on plane surface. The poured plates were left at room temperature to solidify and incubate at $37^{\circ} \mathrm{C}$ overnight to check the sterility of plates. The plates were dried at $50^{\circ} \mathrm{C}$ for 30 minutes before use.

\section{Revival of the fungal cultures}

The fungal cultures used in the study were obtained in lyophilized form. With the help aseptic techniques the lyophilized cultures are inoculated in sterile potato dextrose broth than incubated for 24 hours at $37^{\circ} \mathrm{C}$. After incubation the growth is observed in the form of turbidity. These broth cultures were further inoculated on to the potato dextrose agar plates with loop full of fungus and further incubated for next 24 hours at $37^{\circ} \mathrm{C}$ to obtain the pure culture and stored as stocks that are to be used in further research work.

\section{Anti fungal sensitivity}

The anti fungal sensitivity test is employed on to the microbes against Candida Albicans. For this experiment 6 $\mathrm{mm}$ diameter wells, stock of $30 \mu \mathrm{g} / \mathrm{ml}$ of given sample separately applied on it. A potato dextrose plate is seeded with particular fungus with the help of spread plate technique prior and left for 5 minutes then incubated for 24 hours at $37^{\circ} \mathrm{C}$. After incubation, plates were observed to see the sensitivity of formulation towards test bacteriums at particular concentration in the form zone of inhibition.

\section{Antibiogram Studies}

Broth cultures of the pure culture isolates of those test microorganisms which are sensitive towards the formulations used in present study were prepared by transferring a loop of culture into sterile potato dextrose broth and incubated at $37^{\circ} \mathrm{C}$ for $24-48$ hours. A loop full was taken from these broths and seeded onto sterile potato dextrose agar plates through sterile cotton swab to develop diffused heavy lawn culture. The well diffusion method was used to determine the antifungal activity of formulation of rice bran wax using standard procedure (Bauer, 1966). There were 3 concentration used which are 30,20 and $10 \mu \mathrm{g} / \mathrm{ml}$ for each formulations in antibiogram studies. It's essential feature is the placing of wells with the antibiotics on the surfaces of agar immediately after inoculation with the organism tested. Undiluted over night broth cultures should never be used as an inoculums. The plates were incubated at $37^{\circ} \mathrm{C}$ for $24 \mathrm{hr}$. and then examined for clear zones of inhibition around the wells impregnated with particular concentration of drug.

\section{Stability studies}

Stability studies of optimize formulation of cream, ointment and gel

The prepared gels were packed in aluminium collapsible tubes and subjected to stability studies at $40 \pm 2^{\circ} \mathrm{C} / 75 \pm 5 \%$ $\mathrm{RH}$ and $30 \pm 2^{\circ} \mathrm{C} / 60 \pm 5 \% \mathrm{RH}$ as per ICH guidelines for a period of 3 months. Samples were withdrawn at 1 month time intervals and evaluated for physical appearance, $\mathrm{pH}$, rheological properties, drug content and in vitro drug release.

\section{RESULTS AND DISCUSSION}

Topical gel formulation was developed using rice bran wax. Polymer and active drug concentration were chosen as independent variables while spreadability, extrudability and viscosity as dependent factors. In order to carry out an overview and a critical analysis of skin decontamination, topical lotion formulation was developed successfully and analyzed for decontamination efficacy and dermal toxicity applying the different formulas and statistical approaches.

\section{Characterization of gel formulation}

Table 3: Characterization of formulations $G_{E 1}$ to $G_{E 4}$

\begin{tabular}{|c|c|c|c|c|}
\hline \multirow{2}{*}{ Parameters } & \multicolumn{4}{|c|}{ Formulation } \\
\hline & $\mathrm{G}_{\mathrm{E} 1}$ & $\mathrm{G}_{\mathrm{E} 2}$ & $\mathrm{G}_{\mathrm{E} 3}$ & $\mathrm{G}_{\mathrm{E} 4}$ \\
\hline Physical Appearance & $\begin{array}{l}\text { Translucent, white, } \\
\text { smooth on application }\end{array}$ & $\begin{array}{l}\text { Translucent, white, } \\
\text { smooth on application }\end{array}$ & $\begin{array}{l}\text { Translucent, white, } \\
\text { smooth on application }\end{array}$ & $\begin{array}{l}\text { Translucent, white, } \\
\text { smooth on application }\end{array}$ \\
\hline pH & $7.01 \pm 0.3$ & $6.82 \pm 0.1$ & $6.95 \pm 0.6$ & $6.90 \pm 0.8$ \\
\hline Viscosity (CP) & $30514 \pm 7.3$ & $31412 \pm 16.4$ & $32878 \pm 22.8$ & $31454 \pm 4.6$ \\
\hline Spreadability (gm.cm/sec) & $16.46 \pm 4.6$ & $16.31 \pm 0.58$ & $15.54 \pm 1.39$ & $16.35 \pm 1.11$ \\
\hline$\%$ Drug content & $99.10 \pm 0.4$ & $98.20 \pm 0.3$ & $97.70 \pm 0.9$ & $97.78 \pm 0.4$ \\
\hline Extrudability & +++ & +++ & +++ & +++ \\
\hline
\end{tabular}


Table 4: Characterization of formulations $G_{E 5}$ to $G_{E 9}$

\begin{tabular}{|c|c|c|c|c|c|}
\hline \multirow{2}{*}{ Parameters } & \multicolumn{4}{|c|}{ Formulation } & \multirow[b]{2}{*}{$\mathrm{G}_{\mathrm{E} 9}$} \\
\hline & $\mathrm{G}_{\mathrm{E} 5}$ & $\mathrm{G}_{\mathrm{E} 6}$ & $\mathrm{G}_{\mathrm{E} 7}$ & $\mathrm{G}_{\mathrm{E} 8}$ & \\
\hline $\begin{array}{c}\text { Physical } \\
\text { Appearance }\end{array}$ & $\begin{array}{l}\text { Translucent, white, } \\
\text { smooth on } \\
\text { application }\end{array}$ & $\begin{array}{c}\text { Translucent, } \\
\text { white, smooth on } \\
\text { application }\end{array}$ & $\begin{array}{c}\text { Translucent, } \\
\text { white, smooth on } \\
\text { application }\end{array}$ & $\begin{array}{c}\text { Translucent, } \\
\text { white, smooth on } \\
\text { application }\end{array}$ & $\begin{array}{l}\text { Translucent, white, } \\
\text { smooth on application }\end{array}$ \\
\hline Ph & $6.95 \pm 0.3$ & $6.85 \pm 0.1$ & $7 \pm 0.3$ & $7.03 \pm 0.2$ & $7.03 \pm 0.2$ \\
\hline Viscosity (CP) & $32250 \pm 7.3$ & $32554 \pm 16.4$ & $33510 \pm 22.8$ & $34454 \pm 3.6$ & $34815 \pm 3.6$ \\
\hline $\begin{array}{l}\text { Spreadability } \\
\text { (gm.cm/sec) }\end{array}$ & $15.59 \pm 4.5$ & $14.31 \pm 0.58$ & $13.45 \pm 1.39$ & $13.15 \pm 3.10$ & $12.15 \pm 3.10$ \\
\hline \% Drug content & $99.10 \pm 0.4$ & $96.20 \pm 0.3$ & $97.70 \pm 0.9$ & $98.95 \pm 0.4$ & $98.95 \pm 0.4$ \\
\hline Extrudability & +++ & +++ & +++ & +++ & +++ \\
\hline
\end{tabular}

Table 5: Characterization of formulations $G_{F 1}$ to $G_{F 4}$

\begin{tabular}{|c|c|c|c|c|}
\hline \multirow{2}{*}{ Parameters } & \multicolumn{4}{|c|}{ Formulation } \\
\hline & $\mathrm{G}_{\mathrm{F} 1}$ & $\mathrm{G}_{\mathrm{F} 2}$ & $\mathrm{G}_{\mathrm{F} 3}$ & $\mathrm{G}_{\mathrm{F} 4}$ \\
\hline Physical Appearance & $\begin{array}{l}\text { Translucent, white, } \\
\text { smooth on application }\end{array}$ & $\begin{array}{c}\text { Translucent, white, } \\
\text { smooth on application }\end{array}$ & $\begin{array}{l}\text { Translucent, white, } \\
\text { smooth on application }\end{array}$ & $\begin{array}{l}\text { Translucent, white, } \\
\text { smooth on application }\end{array}$ \\
\hline pH & $6.98 \pm 0.2$ & $6.82 \pm 0.2$ & $6.98 \pm 0.3$ & $6.85 \pm 0.4$ \\
\hline Viscosity $(\mathbf{C P})$ & $30145 \pm 8.9$ & $30989 \pm 10.2$ & $31547 \pm 12.5$ & $32569 \pm 3.6$ \\
\hline Spreadability (gm.cm/sec) & $15.21 \pm 2.1$ & $14.56 \pm 0.21$ & $14.54 \pm 2.87$ & $13.56 \pm 2.45$ \\
\hline$\%$ Drug content & $98.89 \pm 0.25$ & $98.69 \pm 0.35$ & $98.98 \pm 0.45$ & $98.75 \pm 0.35$ \\
\hline Extrudability & +++ & +++ & +++ & +++ \\
\hline
\end{tabular}

$$
\text { +++ Excellent, ++ Good, + Satisfactory }
$$

Table 6: Characterization of formulations $G_{\mathrm{E} 5}$ to $\mathrm{G}_{\mathrm{E} 9}$

\begin{tabular}{|c|c|c|c|c|c|}
\hline \multirow{2}{*}{ Parameters } & \multicolumn{4}{|c|}{ Formulation } & \\
\cline { 2 - 6 } Physical Appearance & $\mathrm{G}_{\mathrm{F} 5}$ & $\mathrm{G}_{\mathrm{F} 6}$ & $\mathrm{G}_{\mathrm{F} 7}$ & $\mathrm{G}_{\mathrm{F} 8}$ & $\mathrm{G}_{\mathrm{F} 9}$ \\
\hline Ph & $\begin{array}{c}\text { Translucent, } \\
\text { white, smooth } \\
\text { on application }\end{array}$ & $\begin{array}{c}\text { Translucent, } \\
\text { white, smooth on } \\
\text { application }\end{array}$ & $\begin{array}{c}\text { Translucent, } \\
\text { white, smooth } \\
\text { on application }\end{array}$ & $\begin{array}{c}\text { Translucent, } \\
\text { white, smooth on } \\
\text { application }\end{array}$ & $\begin{array}{c}\text { Translucent, } \\
\text { white, smooth on } \\
\text { application }\end{array}$ \\
\hline Viscosity (CP) & $6.95 \pm 0.3$ & $6.85 \pm 0.1$ & $7 \pm 0.3$ & $7.03 \pm 0.2$ & $7.03 \pm 0.2$ \\
\hline Spreadability (gm.cm/sec) & $32458 \pm 4.5$ & $32569 \pm 10.5$ & $33568 \pm 10.1$ & $34548 \pm 2.5$ & $34987 \pm 4.2$ \\
\hline \% Drug content & $99.45 \pm 0.32$ & $98.98 \pm 0.21$ & $98.98 \pm 0.12$ & $98.98 \pm 0.4$ & $99.15 \pm 0.43$ \\
\hline Extrudability & $\mathbf{+ + +}$ & $\mathbf{+ + +}$ & $\mathbf{+ + +}$ & +++ & +++ \\
\hline
\end{tabular}

\section{In-vitro drug release studies of $\mathrm{G}_{\mathrm{E} 1}$ to $\mathrm{G}_{\mathrm{E} 9}$ formulation}

The drug release from the gel is based on concentration of rice bran wax used for formulation. The gel formulations GE1, GE2, GE3, GE4, GE5, GE6, GE7, GE8 and GE9 containing $0.1 \%, 0.15 \%, 0.20 \%, 0.25 \%, 0.30 \%, 0.35 \%$, $0.45 \%, 0.50 \%$ of carbopol with rice bran wax $0.5 \%, 0.45 \%$, $0.40 \%, 0.35 \%, 0.30 \%, 0.25 \%, 0.20 \%, 0.15 \%, 0.10 \%$ and $0.05 \%$ showed $82.56 \%, 85.45 \%, 93.32 \%, 96.56 \%, 99.89 \%$, $98.79 \%, 99.10 \%, 99.87 \%$, and $99.98 \%$ drug released at the end of $120 \mathrm{~min}$ respectively. Drug release was inversely proportional to the amount of polymer (Rice bran wax) present in the system i.e. the rate and extent of drug release increases with decrease in total polymeric content of the

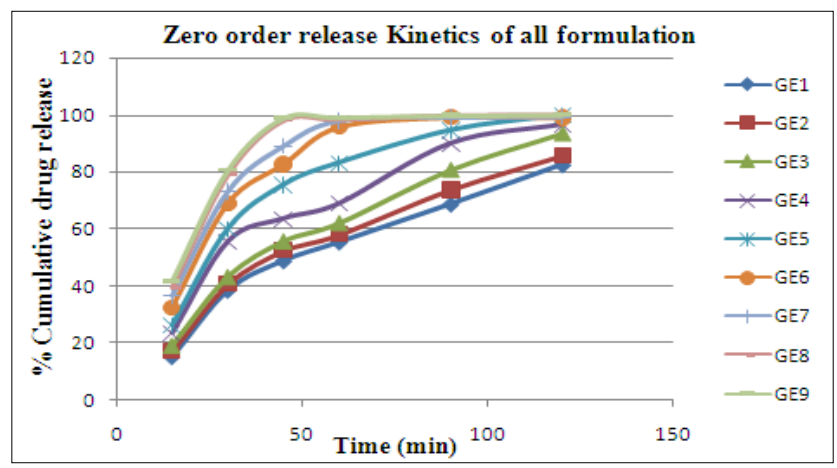

Figure 1: Zero order release kinetics of all formulation system. Increasing Rice bran wax concentration decreased initial burst release and retards further drug release from the gel observed in formulations GE5. Among all formulations, GE5 containing $0.30 \%$ of Rice bran wax showed maximum $99.89 \%$ drug release in $120 \mathrm{~min}$, which indicated that this concentration of wax can be used as an effective rate controlling wax, to retard the release of econazole for long period of time i.e. up to $120 \mathrm{~min}$. Same concentration of rice bran wax used to formulate gel using second model drug 5FU and approximate same results found as econazole cream. The selected formulation GE1 and GF1 was subjected to stability study as per ICH guidelines.

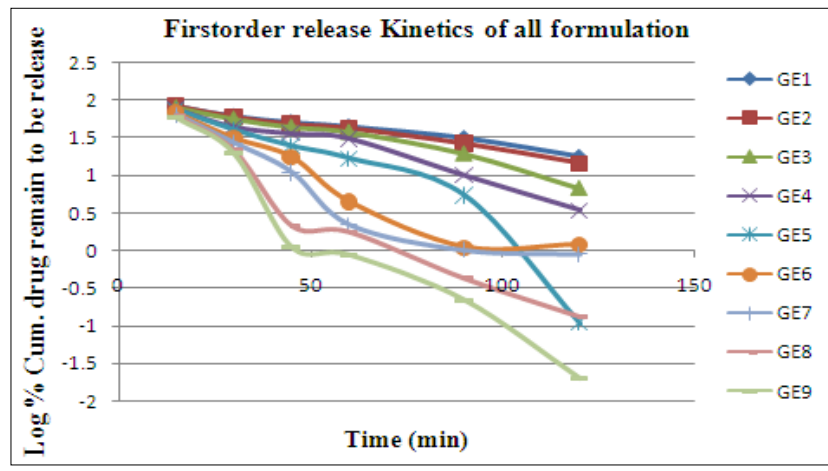

Figure 2: First order release kinetics of all formulation 


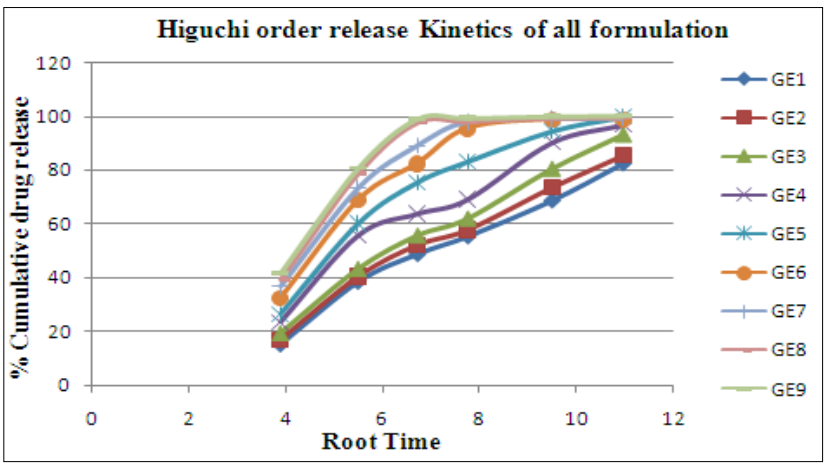

Figure 3: Higuchi matrix release kinetics data

Drug release kinetics with model fitting of econazole gel

These values of in-vitro release were attempted to fit into various mathematical models, plot of zero order, first order, higuchi matrix and peppas. These values were compared with each other for model fitting equation. Based on the highest regression values (r), the best fit model for all the

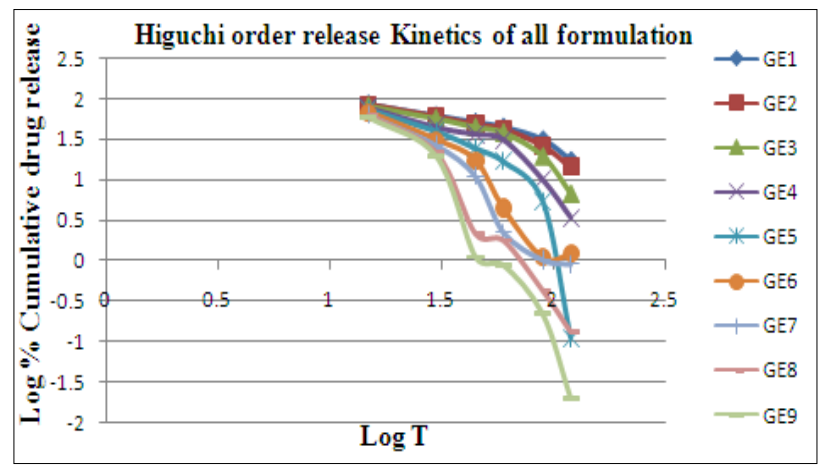

Figure 4: Peppas release kinetics data

formulations was zero order release kinetics. Further Korsmeyer and Peppas equation resulted into the values of $\mathrm{n}>1$, which appears to indicate that the release from the prepared optimized gel formulation (GE5) follows Higuchi order release Kinetics.

Table 7: Correlation coefficient of Model fitting $\left(\mathrm{r}^{2}\right)$

\begin{tabular}{|c|c|c|c|c|c|}
\hline \multirow{2}{*}{ Formulation code } & \multicolumn{3}{|c|}{ Correlation coefficient of Model fitting $\left(\mathbf{R}^{\mathbf{2}}\right)$} & \multirow{2}{*}{ Best fit model } \\
\cline { 2 - 5 } & Zero order & First order & Higuchi matrix & Peppas kinetics & \\
\hline GE1 & 0.931 & 0.942 & 0.979 & 0.943 & Higuchi \\
\hline GE2 & 0.929 & 0.989 & 0.980 & 0.898 & First order \\
\hline GE3 & 0.942 & 0.969 & 0.986 & 0.822 & Higuchi \\
\hline GE4 & 0.881 & 0.973 & 0.947 & 0.833 & Higuchi \\
\hline GE5 & 0.796 & 0.888 & 0.896 & 0.696 & Higuchi \\
\hline GE6 & 0.666 & 0.909 & 0.792 & 0.927 & First order \\
\hline GE7 & 0.605 & 0.880 & 0.738 & 0.945 & Peppas \\
\hline GE8 & 0.513 & 0.926 & 0.649 & 0.967 & Peppas \\
\hline GE9 & 0.497 & 0.942 & 0.633 & 0.943 & Peppas \\
\hline
\end{tabular}

In-vitro drug release studies of $G_{F 1}$ to $G_{F 9}$ formulation

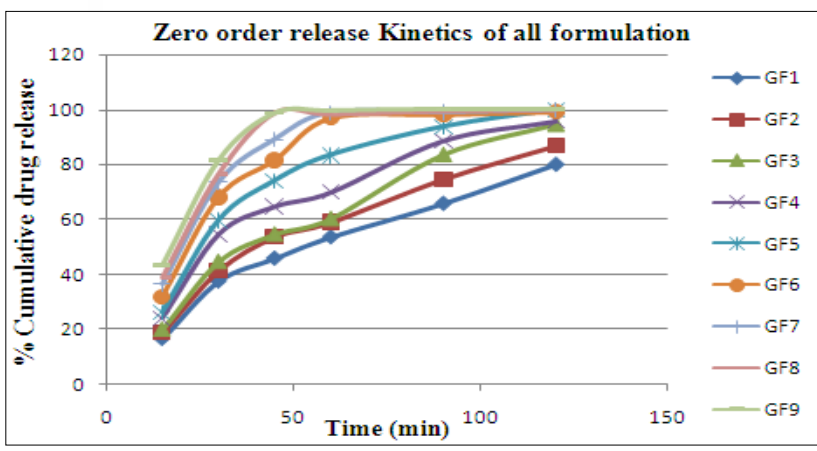

Figure 5: Zero order release kinetics of all formulation

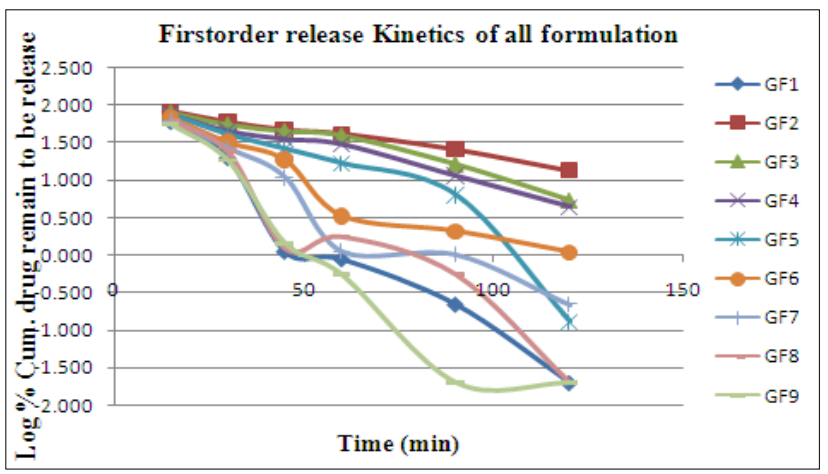

Figure 6: First order release kinetics of all formulation

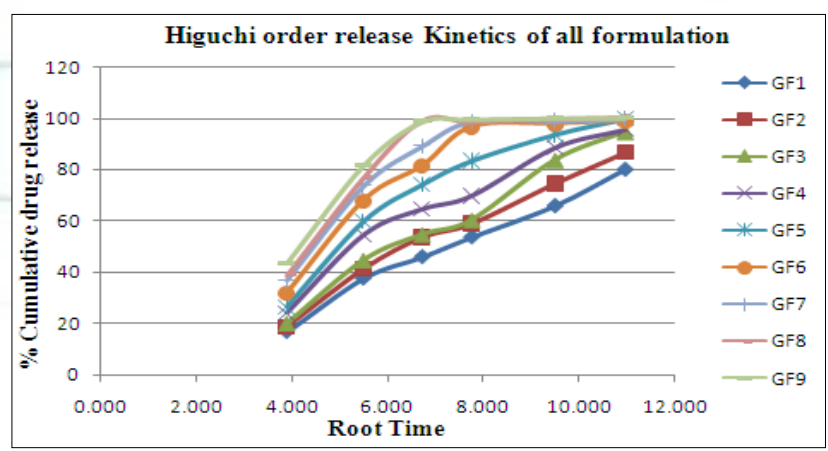

Figure 7: Higuchi matrix release kinetics data

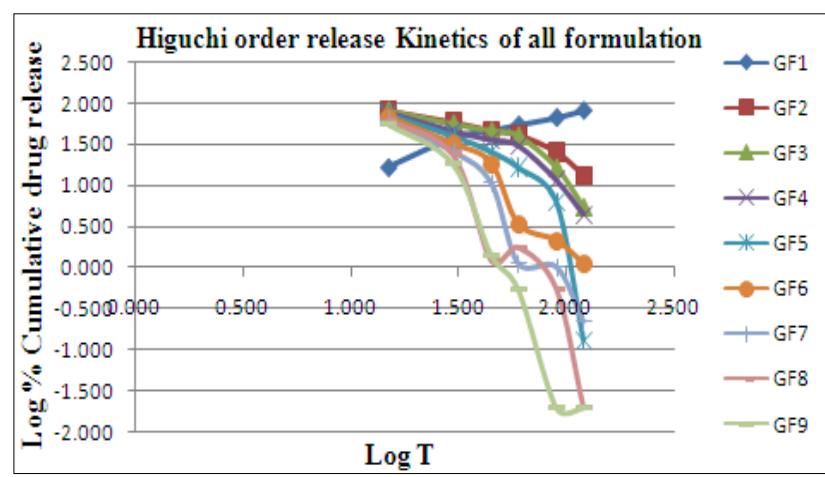

Figure 8: Peppas release kinetics data 
Drug release kinetics with model fitting of 5Fluorouracil gel

These values of in-vitro release were attempted to fit into various mathematical models, plot of zero order, first order, higuchi matrix and peppas. These values were compared with each other for model fitting equation. Based on the highest regression values ( $r$ ), the best fit model for all the formulations was zero order release kinetics. Further Korsmeyer and Peppas equation resulted into the values of $\mathrm{n}>1$, which appears to indicate that the release from the prepared optimized gel formulation (GF5) follows higuchi order release Kinetics.

Table 8: Correlation coefficient of Model fitting $\left(\mathrm{r}^{2}\right)$

\begin{tabular}{|l|l|l|l|l|l|}
\hline \multirow{2}{*}{ Formulation code } & \multicolumn{3}{|l|}{ Correlation coefficient of Model fitting $\left(\mathbf{R}^{\mathbf{2}}\right)$} & \multirow{2}{*}{ Best fit model } \\
\cline { 2 - 6 } & Zero order & First order & Higuchi matrix & Peppas kinetics & \\
\hline GF1 & 0.946 & 0.941 & 0.986 & 0.956 & Higuchi \\
\hline GF2 & 0.932 & 0.988 & 0.982 & 0.890 & First order \\
\hline GF3 & 0.949 & 0.962 & 0.984 & 0.799 & Higuchi \\
\hline GF4 & 0.879 & 0.982 & 0.949 & 0.860 & First order \\
\hline GF5 & 0.804 & 0.882 & 0.902 & 0.691 & Higuchi \\
\hline GF6 & 0.667 & 0.915 & 0.792 & 0.934 & Peppas \\
\hline GF7 & 0.603 & 0.917 & 0.736 & 0.921 & Peppas \\
\hline GF8 & 0.520 & 0.917 & 0.655 & 0.883 & First order \\
\hline GF9 & 0.498 & 0.921 & 0.634 & 0.942 & Peppas \\
\hline
\end{tabular}

\section{Characterization of gel formulation}

Table 9: Results of Characterization of optimized formulation formulations $G_{E 5}$ and $G_{F 5}$

\begin{tabular}{|l|l|l|}
\hline \multirow{2}{*}{ Parameters } & Formulation \\
\cline { 2 - 3 } & $\mathrm{G}_{\mathrm{E} 5}$ & $\mathrm{G}_{\mathrm{F} 5}$ \\
\hline Physical Appearance & Translucent, white, smooth on application & Translucent, white, smooth on application \\
\hline Ph & $6.95 \pm 0.3$ & $6.95 \pm 0.3$ \\
\hline Viscosity $(\mathbf{C P})$ & $32250 \pm 7.3$ & $32458 \pm 4.5$ \\
\hline Spreadability $(\mathbf{g m . c m} / \mathbf{s e c})$ & $15.59 \pm 4.5$ & $13.45 \pm 2.5$ \\
\hline \% Drug content & $99.10 \pm 0.4$ & $99.45 \pm 0.32$ \\
\hline Extrudability & $\mathbf{+ + +}$ & $\mathbf{+ + +}$ \\
\hline
\end{tabular}

Drug release kinetics with model fitting of econazole and 5 fluorouracil gel

The data of in-vitro release of formulations was applied on different drug release kinetic model to determine release kinetic profile. The various mathematical models like zero order, first order, higuchi matrix and peppas. These values were compared with each other for model fitting equation.
Based on the highest regression values (r), the best fit model for all the gel formulations was zero order release kinetics. Higuchi order release Kinetics resulted into the values of $n>1$, which indicated that the release from the prepared optimized gel formulation (GE5) follows Higuchi order release Kinetics.

Table 10: Correlation coefficient of Model fitting $\left(\mathrm{r}^{2}\right)$

\begin{tabular}{|l|l|l|l|l|l|}
\hline \multirow{2}{*}{ Formulation code } & \multicolumn{3}{|l|}{ Correlation coefficient of Model fitting $\left(\mathbf{R}^{\mathbf{2}}\right)$} & \multirow{2}{*}{ Best fit model } \\
\cline { 2 - 5 } & Zero order & First order & Higuchi matrix & Peppas kinetics & \\
\hline GE5 & 0.796 & 0.888 & 0.896 & 0.696 & Higuchi \\
\hline GF5 & 0.804 & 0.882 & 0.902 & 0.691 & Higuchi \\
\hline
\end{tabular}

Eighteen formulations of gel were prepared nine formulations of econazole and nine formulations of 5fluorouracil as model drug.

Gel of econazole and 5-fluorouracil prepared by using rice bran wax. Result shows that the physical appearances of the gel formulations were Translucent, white and smooth on application. The $\mathrm{pH}$ of the gel formulations was in the range of $6.82 \pm 0.1$ to $7.03 \pm 0.2$, which lies in the normal $\mathrm{pH}$ range of the skin. The $\mathrm{pH}$ of optimized formulation of econazole loaded gel found to be $6.90 \pm 0.8$ and $\mathrm{pH}$ of formulation of $5 \mathrm{FU}$ loaded gel was found to be $7.03 \pm 0.2$, which is considered acceptable to avoid the risk of irritation upon application to the skin.

Viscosity of prepared gel was determined by using Brookfield Viscometer and were ranging between $30,250 \pm 7.3 \mathrm{cp}$ to $32878 \pm 2.8 \mathrm{cp} \&$ the optimized formulation of econazole loaded gel $\left(\mathrm{G}_{\mathrm{E} 5}\right)$ was found to be $31454 \pm 4.6$ $\mathrm{cp}$ and viscosity of optimized formulation of $5 \mathrm{FU}\left(\mathrm{G}_{\mathrm{F} 5}\right)$ loaded gel was found $31454 \pm 3.6 \mathrm{cp}$. The values of spread ability indicated that the gels were easily spreadable by small amount of shear. Spreading of optimized formulation of econazole $\left(\mathrm{G}_{\mathrm{E} 5}\right)$ and 5-fluorouracil $\left(\mathrm{G}_{\mathrm{F} 5}\right)$ gel were found to be $16.31 \pm 0.58 \mathrm{gm} . \mathrm{cm} / \mathrm{sec}$ and $20.59 \pm 4.5$ 
gm.cm/sec respectively, which indicates good spread ability of gel.

Release of drug from gel base was significantly slower, which confirmed that slight prolonged drug release rate. Incorporation of rice bran wax affected the release rate of the drug. By increasing the amount of wax, the release rate of the drug decreased, which could be related to the increased rigidity of the formulation, followed by its decreased permeability for the drug.

The drug release from the gel is based on concentration of rice bran wax used for formulation. The gel formulations GE1, GE2, GE3, GE4, GE5, GE6, GE7, GE8 and GE9 containing $0.1 \%, 0.15 \%, 0.20 \%, 0.25 \%, 0.30 \%, 0.35 \%$, $0.45 \%, 0.50 \%$ and $0.55 \%$ of carbopol with rice bran wax $0.55 \%, 0.50 \%, 0.45 \%, 0.40 \%, 0.35 \%, 0.30 \%, 0.25 \%$, $0.20 \%$, and $0.15 \%$ showed $82.56 \%, 85.45 \%, 93.32 \%$, $96.56 \%, 99.89 \%, 98.79 \%, 99.10 \%, 99.87 \%$, and $99.98 \%$ drug released at the end of $120 \mathrm{~min}$ respectively. Drug release was inversely proportional to the amount of polymer (Rice bran wax) present in the system i.e. the rate and extent of drug release increases with decrease in total polymeric content of the system. Increasing Rice bran wax concentration decreased initial burst release and retards further drug release from the gel observed in formulations GE5 and GF5. Among all formulations, GE5 and GF5 containing $0.35 \%$ of Rice bran wax showed maximum $99.89 \%$ and $93.69 \%$ drug release respectively in $120 \mathrm{~min}$, which indicates that this concentration of wax can be used as an effective rate controlling wax, to retard the release of econazole for long period of time i.e. up to $120 \mathrm{~min}$.

These values of in-vitro release were attempted to fit into various mathematical models, plot of zero order, first order, higuchi matrix and peppas. These values were compared with each other for model fitting equation. Based on the highest regression values ( $r$ ), the best fit model for all the formulations was zero order release kinetics. Further Korsmeyer and Peppas equation resulted into the values of $\mathrm{n}>1$, which appears to indicate that the release from the GE5 $(\mathrm{r}$ value $=0.896)$ and GF5 $(\mathrm{r}$ value $=0.902)$ follows Higuchi order release Kinetics.

\section{Cytotoxicity assay}

In vitro cytotoxic activity was conducted for 5 FC loaded gel against Cell line. Result shows that inhibition of cell line by gel containing 5 FC at all concentrations. The IC50 values for gel were found to be $0.6 \mathrm{ug} / \mathrm{ml}$ respectively.

\section{Anti fungal activity}

In vitro anti fungal activity was conducted for econazole loaded gel against Candida Albicans. Result shows that Candida albicans was inhibited by the standard antifungal agent (econazole), at all the concentration $(30 \mu \mathrm{g} / \mathrm{ml})$. Prepared formulations of econazole loaded gel showed greater percentage of inhibition against Candida albicans indicating higher antifungal activity as compared with marketed formulation of econazole due to synergistic effect with rice bran wax.

\section{Skin irritation test}

As all these formulations were prepared for their topical use hence tested for skin irritation. The effect of formulations on the rat skin was observed after 24,48 , and $72 \mathrm{~h}$. The result shows that there were no physical and chemical changes and negligible skin irritation scores in case of all formulations; Hence, the prepared formulations can be considered to be safe for topical application.

\section{Stability studies}

Stability studies for prepared cream, ointment and gels were conducted at $40 \pm 2^{\circ} \mathrm{C} / 75 \pm 5 \% \mathrm{RH}$ and $30 \pm 2^{\circ} \mathrm{C} / 60 \pm 5 \%$ RH as per ICH guidelines for a period of 3 months. Results of stability studies clearly indicates that optimized batches of gel (GE5 \& GF5) were stable over the chosen temperature and humidity up to 3 months as were no significant variation in drug release from these formulation.

\section{CONCLUSION}

Rice bran wax based formulations (Gel) of 5FU and econazole have good appearance, homogeneity, viscosity, wash ability, release pattern, less irritant with good Anticancer and Antifungal activity respectively. These formulations have potential advantages over marketed preparations as they improve patient compliance by rapid local onset of action for longer period with cost effectiveness. Hence present study concludes that rice bran wax is excellent base for preparation of semisolid formulations including cream, ointment and gel, suitable substitute for car carnauba wax as a base for semisolid formulations and in some extent it can be used as release retardant agent in sustained release dosage form.

\section{REFERENCES}

1. Bodmier R, Hermann J. Encyclopedia of Pharmaceutical Techonology. Vol. 16. In: Swarbrick J, Boylan JC, editors. Waxes. New York: Marcel Deckker, Inc.; 1997: 335-361.

2. Adair CR. Rice chemistry and technology. In: Houston DF, editor. Production and Utilization of rice. 2nd ed. St. Paul, MN: AACC; 1972:15-44.

3. Neha K, Nirmala HSL, Insitu gelling system: A Review, J Drug Del and Therapeutics. 2014; 4(4):93-103

4. Mujahid M, Ahmad L, Ahmad M, Synthesis of ZnO nanogel for the treatment of superficial skin microbial infections, Journal of Drug Delivery and Therapeutics. 2017; 7(2):58-61

5. Farooqi. Herbal skin care formulation and process for the preparation thereof, U.S. Patent US 6368639, 2002.

6. Pandya K, Aggarwal P, Dashora A, Sahu d, Garg R, Pareta LK, Menaria M, Joshi B, Formulation and evaluation of oral floatable in-situ gel of ranitedine hydrochloride, Journal of Drug Delivery and Therapeutics. 2013; 3(3):90-97

7. Saarinen-Savolainen $P$, Jarvinen $T$, Taipale H, Urtti A. Method for evaluating drug release from liposomes in sink conditions. Int J Pharm 1997; 159:27-33.

8. Kulkarni SK, Jain NK. Pharmacological and pharmacokineti $\mathrm{c}$ studies on marketed gel formulations of nimesulide, India $\mathrm{n}$ Drugs 2001; 38:63-66.

9. Lachman, Leon; et al; "The Theory and Practice of Industrial Pharmacy" Varghese publication, India, 3rd edition 1987: 534- 562.

10. Sachan A, Gupta A, Arora M. "Formulation \& characterization of nanostructured lipid carrier (NLC) based gel for topical delivery of etoricoxib." Journal of Drug Delivery and Therapeutics, 2016; 6(2):4-13. 